\title{
A Bridging Double Bond as an Electron Acceptor for Optical Nonlinearity of Furan-Containing [n.2]Cyclophenes**
}

\author{
Hsin-Chieh Lin, Wei-Yu Lin, Hao-Tien Bai, Jia-Hong Chen, Bih-Yaw Jin, and Tien-Yau Luh*
}

\author{
Dedicated to Professor Sunney I. Chan on the occasion of his 70th birthday
}

Studies on the relationship between the structures of organic conjugated systems and their molecular hyperpolarizabilities have been extensive because they may provide useful information for the application of nonlinear optical (NLO) properties in electrooptical devices. $^{[1]}$ The criterion for an organic molecule to exhibit second-order optical nonlinearity is the lack of a center of symmetry. The presence of donor and acceptor moieties conjugated with the linking $\pi$ system is known to facilitate the formation of intramolecular charge transfer, which will induce second-order NLO properties. ${ }^{[1]}$ Recently, a series of [2.2]paracyclophane deriva-

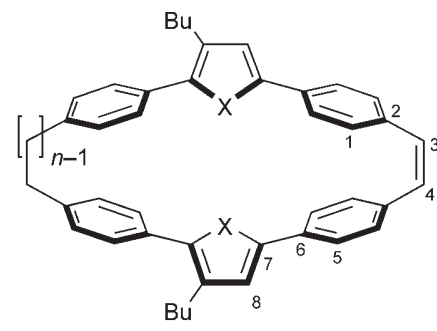

1a $X=O, n=2$ 1b $X=0, n=3$ 1c $X=O, n=4$ 1d $X=O, n=5$ 1e $X=0, n=6$ 1f $\mathrm{X}=\mathrm{O}, n=12$ 1g X $=\mathrm{S}, n=2$ tives has been shown to demonstrate three-dimensional dipolar and octupolar NLO properties as a result of through-space delocalization of the chromophores. $^{[2]}$ [2.2]Metacyclophenes and metacyclophanedienes can readily undergo electrocyclization to yield the corresponding bridged annulene derivatives. ${ }^{[3]}$ Presumably, interactions between the arene moieties and the bridging double bond(s) may take place. Five-membered heterophanes can be viewed as analogues of metaphanes; however, the chemistry of five-membered [2.2] heterophenes and heterophanedienes has been only sporadically explored, ${ }^{[4,5]}$ even though the five-membered heteroaromatic rings are electron rich. ${ }^{[6,7]}$ It is envisioned that interactions between the heteroarene rings and the bridging double bond(s) in [2.2]heterophenes may lead to a dipolar resonance structure.

Recently, we reported that furan-containing [2.2]cyclophene 1a exhibits extraordinary photophysical properties

[*] Dr. H.-C. Lin, Dr. W.-Y. Lin, H.-T. Bai, J.-H. Chen, Prof. B.-Y. Jin, Prof. T.-Y. Luh

Department of Chemistry

National Taiwan University

Taipei 106 (Taiwan)

Fax: (+886) 223-644-971

E-mail:tyluh@ntu.edu.tw

[**] This work was supported by the National Science Council of the Republic of China.

$\square$ Supporting information for this article is available on the WWW under http://www.angewandte.org or from the author. relative to those of the saturated analogue $2 .^{[5]}$ The emission band of 2 appears at a similar wavelength to that of the unbridged teraryl $\mathbf{3}$ (ca. $380 \mathrm{~nm}$ ). The observation of similar
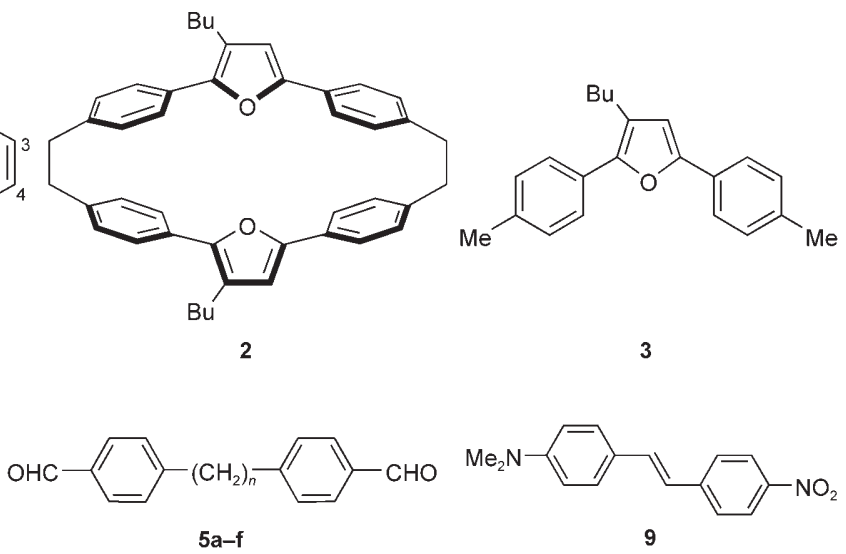

vibronic structures in $\mathbf{2}$ and $\mathbf{3}$ suggests that there is no delocalization between the two teraryl moieties in $\mathbf{2}$. In the absorption spectrum of $\mathbf{1}$ a there is a low-energy band at about $380 \mathrm{~nm}$, as well as an absorption band at about $330 \mathrm{~nm}$ arising from the teraryl chromophore. The emission spectrum of $\mathbf{1 a}$ is striking, with a large Stokes shift $(178 \mathrm{~nm})$ being observed. It seems likely that interactions between the teraryl sections and the double bond in 1 a may be different in the ground and the excited states. The teraryl moieties and the double bond in $\mathbf{1 a}$ are clearly not in the same plane. Recently, it has been shown that chromophores with twisted $\pi$-electron systems in a biaryl system having charged donor and acceptor moieties exhibit ultralarge molecular hyperpolarizability with exceptionally high $\mu \beta$ values. ${ }^{[8]}$ It is therefore envisaged that $\mathbf{1 a}$ may have second-order NLO activity even in the absence of any apparent electron-withdrawing substituents. We now report a systematic investigation of the NLO properties of a series of [n.2]cyclophenes $\mathbf{1}$ with tethering chains of different lengths.

Furan-containing cyclophenes 1a-f were synthesized according to Scheme $1 .^{[9]}$ Thiophene analogue $\mathbf{1 g}$ was prepared in a similar manner ${ }^{[10]}$ (see the Supporting Information).

Electric-field-induced second-harmonic generation (EFISH) measurements at $1.91 \mu \mathrm{m}$ were employed for the NLO investigations. ${ }^{[11]}$ The photophysical properties and the $\mu \beta$ values for $\mathbf{1}$ as well as the reference compound 9 are summarized in Table 1 . The absorption and emission spectra of selected [ $n .2]$ cyclophenes $(\mathbf{1} \mathbf{a}, \mathbf{1 c}, \mathbf{1 e}$, and $\mathbf{1 f})$ are shown in 


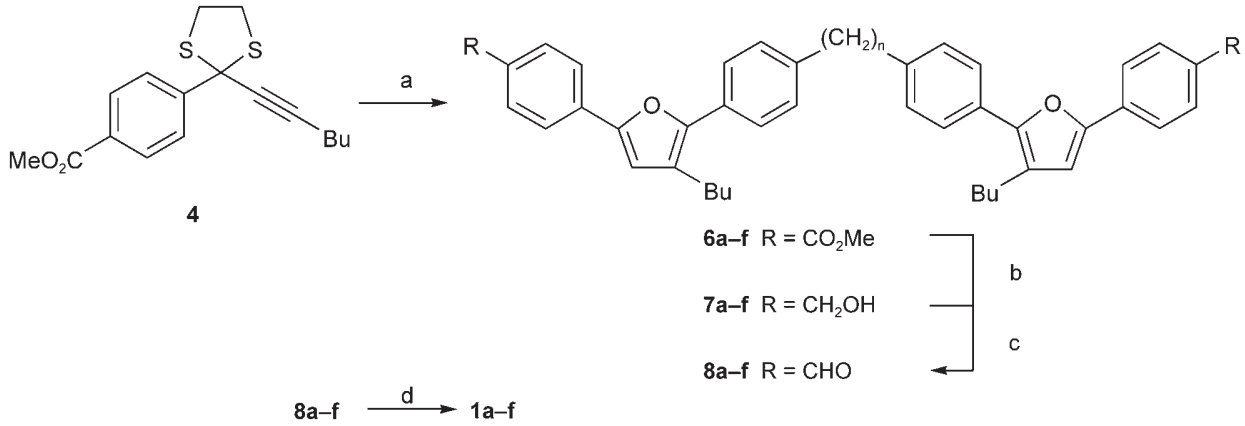

Scheme 1. a) 1. $n \mathrm{BuLi}, \mathrm{THF},-78^{\circ} \mathrm{C}, 50 \mathrm{~min} ; 2.5 \mathrm{a}-\mathrm{f}, \mathrm{THF},-78^{\circ} \mathrm{C}, 1 \mathrm{~h}$; RT, $30 \mathrm{~min}, 3 . \mathrm{TFA}, \mathrm{RT}, 12 \mathrm{~h}$, 40-55\%; b) DIBAL-H, THF, $0^{\circ} \mathrm{C}, 3 \mathrm{~h}, 89-98 \%$; c) $\mathrm{MnO}_{2}, \mathrm{CH}_{2} \mathrm{Cl}_{2}, \mathrm{RT}, 6 \mathrm{~h}, 90-97 \%$; d) $\mathrm{TiCl}_{4}, \mathrm{Zn}$, Py, reflux, $16 \mathrm{~h}, 25-75 \%$. TFA = trifluoroacetic acid, DIBAL-H = diisobutylaluminum hydride, $\mathrm{Py}=$ pyridine. tailing at longer wavelengths. They all showed large Stokes shifts $(157-179 \mathrm{~nm})$. These results suggested that there might be significant difference in the delocalization in the ground and excited states in these substrates. The quantum yields of $\mathbf{1 e}$ and $\mathbf{1} \mathbf{f}$ were higher than those of 1a-d. Apparently, the relief of the strain arising from the increase in the length of the tethering chain may result in better conjugation between the teraryl chromophores and the bridged double

Figure 1 (the spectra of the other compounds can be found in the Supporting Information).

The spectra of all the cyclophenes $\mathbf{1}$ exhibited, in addition to the absorptions arising from the teraryl chromophores,

Table 1: Photophysical and $\mu \beta$ values of 1 and related compounds in $\mathrm{CHCl}_{3}$.

\begin{tabular}{|c|c|c|c|c|c|c|c|}
\hline Compound & $\lambda_{\max }[\mathrm{nm}]$ & $\lambda_{\mathrm{em}}[\mathrm{nm}]$ & $\Phi^{[a]}$ & $\mu[D]^{[b]}$ & $\omega^{[b, c]}$ & $\chi^{[\mathrm{b}, \mathrm{d}]}$ & $\mu \beta_{1.91^{[e]}}$ \\
\hline $1 \mathrm{a}$ & 325 & 501 & 0.28 & 1.12 & 40.1 & 20.7 & 232 \\
\hline $1 \mathrm{~b}$ & 327 & 506 & 0.32 & 1.23 & $39.8^{[f]}$ & $18.5^{[f]}$ & 370 \\
\hline $1 c$ & 330 & 496 & 0.36 & 1.26 & 38.7 & 16.3 & 530 \\
\hline $1 \mathrm{~d}$ & 330 & 498 & 0.39 & 1.29 & $38.5^{[f]}$ & $15.5^{[f]}$ & 502 \\
\hline $1 \mathrm{e}$ & 331 & 498 & 0.51 & 1.48 & 31.9 & 14.5 & 110 \\
\hline $1 \mathrm{f}$ & 337 & 494 & 0.57 & 1.05 & 24.6 & 1.2 & 3 \\
\hline $1 \mathrm{~g}$ & 314 & 491 & 0.22 & 1.14 & 51.6 & 30.3 & 203 \\
\hline 2 & 315 & 380 & 0.59 & 0.27 & & & n.d. \\
\hline 9 & 430 & & & $6.60^{[\mathrm{g}]}$ & & & 450 \\
\hline
\end{tabular}

[a] Measured in EtOAc using coumarin as a reference $(\Phi=0.99)$ [b] Calculated by DFT at the 6-31G** level. [c] Calculated dihedral angle $\left({ }^{\circ}\right)$ between the $\mathrm{C} 1-\mathrm{C} 2$ and $\mathrm{C} 3-\mathrm{C} 4$ bonds in 1. [d] Calculated dihedral angle $\left({ }^{\circ}\right)$ between the $\mathrm{C} 5-\mathrm{C} 6$ and $\mathrm{C} 7-\mathrm{C} 8$ bonds in 1 . [e] In $10^{-48}$ esu. [f] Compounds $\mathbf{1} \mathbf{b}$ and $\mathbf{1} \mathbf{d}$ contain an odd number of carbon atoms in the tethering chain and do not have a $C_{2}$ symmetry axis, which led to two different $\omega$ and $\chi$ values being obtained ( $1 \mathrm{~b}: \omega=38.5$ and $41.1^{\circ}, \chi=12.5$ and $24.7^{\circ} ; 1 \mathrm{~d}: \omega=37.7$ and $39.4^{\circ}, \chi=12.2$ and $\left.18.9^{\circ}\right)$. The average values are shown in the Table. [g] Ref. [11].

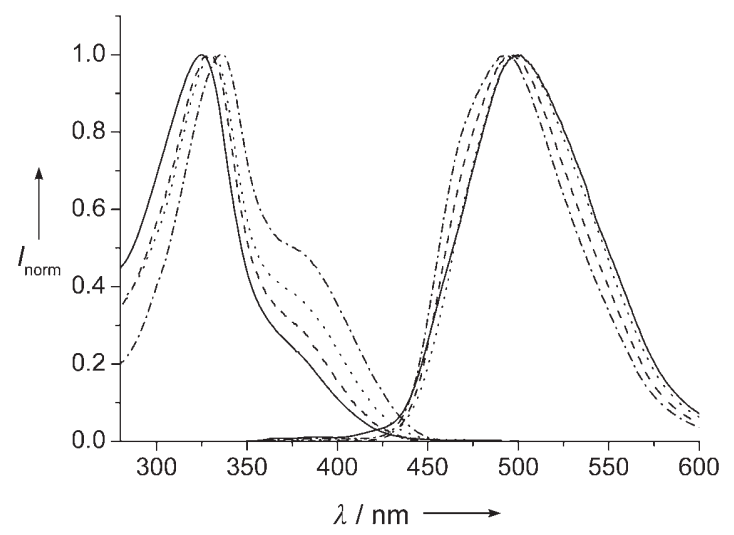

Figure 1. Absorption and emission spectra of 1 a $(-), 1$ c (----), $\mathbf{l e}(\cdot \cdots \cdot)$, and $\mathbf{1} \mathbf{f}(-\cdot-\bullet)$ in $\mathrm{CHCl}_{3}$. bond. This effect can also be evidenced by slight changes in the $\lambda_{\max }$ values with different lengths of the tethering chain.

It is noteworthy that cyclophenes $\mathbf{1} \mathbf{a}-\mathbf{g}$ exhibited secondorder optical nonlinearity. The $\mu \beta$ values for $\mathbf{1 a}-\mathbf{e}$ are two orders of magnitude higher than that of $\mathbf{1} \mathbf{f}$, and that of $\mathbf{1 d}$ is fivefold larger than that of 1e. Surprisingly, the $\mu \beta$ values for $\mathbf{1 b}-\mathbf{d}$ are comparable with that of $\mathbf{9}$. Compound $\mathbf{9}$ has both a strong electron-donating substituent $\left(\mathrm{Me}_{2} \mathrm{~N}\right)$ and a strong electron-withdrawing substituent $\left(\mathrm{NO}_{2}\right)$ linked through a stilbene moiety. The dipole moment for 9 is $6.6 \mathrm{D}^{[12]}$ Cyclophenes $\mathbf{1}$ are much less polar. The calculated dipole moments are given in Table 1. Consequently, it is surprising that $\mathbf{1 a - e}$ exhibited such unusually high $\mu \beta$ values. Furan $\left(\sigma_{\mathrm{p}}=-0.39\right)$ and thiophene rings $\left(\sigma_{\mathrm{p}}=-0.43\right)$ may serve as electrondonating substituents, ${ }^{[6,7]}$ and replacement of the furan ring by the thiophene ring in $\mathbf{1 g}$ essentially did not alter the NLO properties of the cyclophenes. Thus, the $\mu \beta$ value for $\mathbf{1 g}$ is $203 \times 10^{-48} \mathrm{esu}$, which is comparable to that of $\mathbf{1 a}$. The contribution of the double bond to the NLO properties in $\mathbf{1 a}-\mathbf{g}$ is striking. It is noteworthy that $\mathbf{2}$ does not exhibit any nonlinear optical behavior and is essentially nonpolar $(\mu=$ $0.27 \mathrm{D}$ ). These results suggest that the bridging double bond may be viewed as an electron acceptor.

DFT calculations on 1a showed that the distribution of electron density in the highest occupied molecular orbital electron density shifted to the bridging double bond in the lowest unoccupied molecular orbital (LUMO, Figure 2). Such electron distributions in the HOMO and LUMO of $\mathbf{1 a}$ might explain their $\pi$-donor and $\pi$-acceptor behaviors, respectively. ${ }^{[1]}$ Similar behavior was also found in $\mathbf{1 b}-\mathbf{f}$ and thiophene derivative $\mathbf{1 g}$ (see the Supporting Information). On the other hand, the electron distributions in both the HOMO and LUMO of $\mathbf{2}$ were superimposed, and thus no charge transfer would occur (Figure 2).

The dihedral angles $\omega$ formed between the $\mathrm{C} 1-\mathrm{C} 2$ and C3-C4 bonds in $\mathbf{1}$ also decrease with the length of the tethering chain. A plot of the $\mu \beta$ values of $\mathbf{1} \mathbf{a}-\mathbf{f}$ against $\omega$ is shown in Figure 3. It is interesting to note that the $\mu \beta$ value reaches a maximum at $\omega=38.7^{\circ}$ (tethering chain length $=4$ ) and drops abruptly when the value of $\omega$ increases to around $40^{\circ}$ (tethering chain length $=2,3$ ). Presumably, the strain may be relieved significantly when the tethering chain length (HOMO) was highest on the two furan moieties, whereas the 

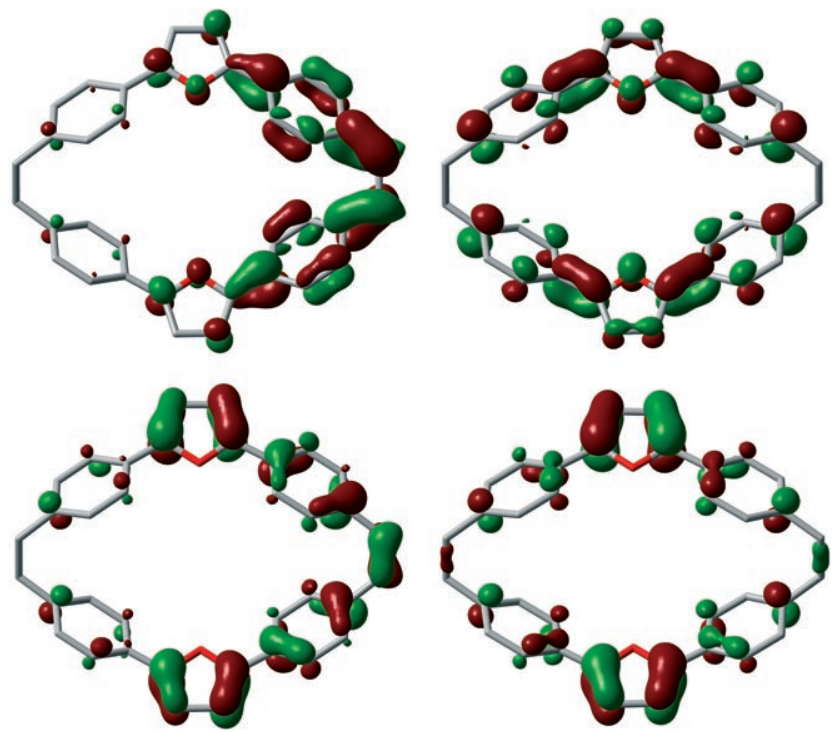

Figure 2. Contour plots of the frontier molecular orbitals obtained by DFT calculations at the B3LYP/6-31G**' level (upper: LUMO, lower: HOMO) of $\mathbf{1}$ a (left) and $\mathbf{2}$ (right). Butyl substituents and hydrogen atoms have been omitted for clarity.

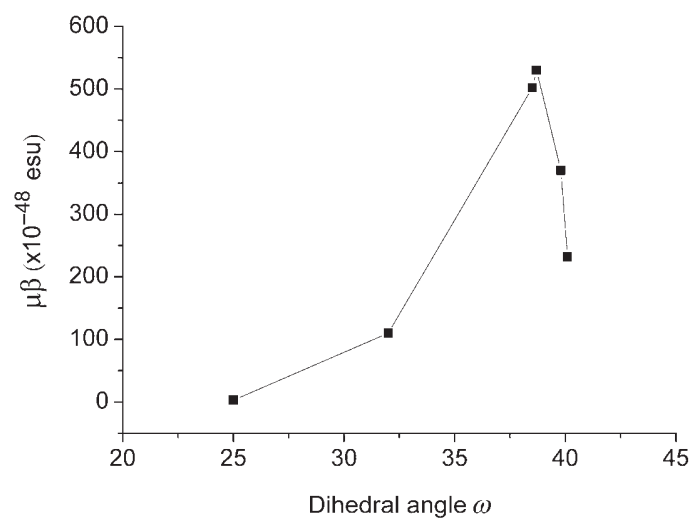

Figure 3. Plot of the $\mu \beta$ values against the dihedral angle $\omega$ for $\mathbf{1} \mathbf{a}-\mathbf{f}$.

increases from three to four methylene groups. Such a twisted $\pi$ system may account for the unusually high $\mu \beta$ values for the cyclophenes $\mathbf{1}^{[8]}$ As the length of the tethering chain increases, both the dihedral angles $\omega$ and the $\mu \beta$ values decrease significantly. Moreover, as shown in Table 1, the dihedral angles $\chi$ between the plane of the furan ring and the plane of the neighboring benzene ring in $\mathbf{1} \mathbf{a}-\mathbf{e}$ are around $14-21^{\circ}$. The nonplanarity of the teraryl systems may also enhance the hyperpolarizability of cyclophenes 1 . On the other hand, the teraryl moiety in $\mathbf{1} \mathbf{f}$ is almost planar $\left(\chi=1^{\circ}\right)$.

It is well documented that $\Lambda$-shaped $C_{2 v}$-symmetric molecules with two donors and one acceptor exhibit enhanced second-order NLO properties. ${ }^{[13]}$ The criterion for such an enhancement would require little interaction between the donor moieties. ${ }^{[13]}$ As mentioned earlier, any interaction between the two teraryl chromophores in $\mathbf{1 a}$ or $\mathbf{2}$ would be negligibly weak, if any. ${ }^{[5]}$ Cyclophenes $\mathbf{1}$ can thus be considered as $\Lambda$-shaped molecules with the furan or thiophene rings as the donors and a double bond as the acceptor.
In summary, we have detailed a new series of furancontaining teraryl cyclophene derivatives 1 which exhibit unusually large Stokes shifts and NLO properties. These cyclophenes $\mathbf{1}$ have neither particularly strong electrondonating moieties nor electron-withdrawing groups and have relatively low polarity. Yet they exhibit exceptionally high $\mu \beta$ values, which are even comparable with that of the highly polar compound 9. Structurally, the strained cyclophenes 1 furnish a unique feature that dictates these unusual photophysical properties: strain results in the $\pi$ systems of the teraryl system and the bridging double bond being twisted. Such a twisted system may thus induce significant enhancement in hyperpolarizability. ${ }^{[8]}$ The five-membered heteroaromatic rings in $\mathbf{1}$ may not only serve as electron donors, but may also accommodate the appropriate geometry to enable the interactions to occur between the oligoaryl systems and the double bond that lead to unusual photophysical and NLO properties.

Received: August 31, 2006

Revised: January 12, 2006

Keywords: cyclophanes - density functional calculations . hyperpolarizability $\cdot$ nonlinear optics $\cdot$ pi interactions

[1] a) Nonlinear Optics of Organic Molecules and Polymers (Eds.: H. S. Nalwa, S. Miyata), CRC, Boca Raton, FL, 1997; b) G. D. L. Torre, P. Vázquez, F. Agulló-López, T. Torres, Chem. Rev. 2004, 104, 3723-3750; c) J. A. Delaire, K. Nakatani, Chem. Rev. 2000, 100, 1817-1846; d) D. R. Kanis, M. A. Ratner, T. J. Marks, Chem. Rev. 1994, 94, 195-242; e) S. Marder, Chem. Commun. 2006, 131, 131-134; f) M. Ahlheim, M. Barzoukas, P. V. Bedworth, M. Blanchard-Desce, A. Fort, Z.-Y. Hu, S. R. Marder, J. W. Perry, C. Runser, M. Staehelin, B. Zysset, Science 1996, 271, $335-337$

[2] a) G. P. Bartholomew, I. Ledoux, S. Mukamel, G. C. Bazan, J. Zyss, J. Am. Chem. Soc. 2002, 124, 13480-13485; b) J. Zyss, I. Ledoux, S. Volkov, V. Chernyak, S. Mukamel, G. P. Bartholomew, G. C. Bazan, J. Am. Chem. Soc. 2000, 122, 11956-11962.

[3] a) H. Blaschke, V. Boekelheide, J. Am. Chem. Soc. 1967, 89, 2747-2748; b) R. H. Mitchell, V. Boekelheide, J. Am. Chem. Soc. 1974, 96, 1547-1557; c) for a review, see: R. H. Mitchell, Eur. J. Org. Chem. 1999, 2695-2703.

[4] a) E. Vogel, N. Jux, J. Dörr, T. Pelster, T. Berg, H.-S. Böhm, F. Behrens, J. Lex, D. Bremm, G. Hohlneicher, Angew. Chem. Int. Ed. 2000, 39, 1101-1105; b) G. Märkl, H. Sauer, P. Kreitmeier, T. Burgemeister, F. Kastner, G. Adolin, H. Nöth, K. Polborn, Angew. Chem. 1994, 106, 1211-1213; Angew. Chem. Int. Ed. Engl. 1994, 33, 1151-1153; c) E. Vogel, M. Sticker, P. Röhrig, H. Schmickler, H. Schmickler, J. Lex, O. Ermer, Angew. Chem. 1988, 100, 450 - 453; Angew. Chem. Int. Ed. Engl. 1988, 27, 411 414; d) J. L. Sessler, M. Cyr, A. K. Burrel, Tetrahedron 1992, 48, 9661-9672; e) Z. Hu, J. L. Atwood, M. P. Cava, J. Org. Chem. 1994, 59, 8071-8075; f) Modern Cyclophane Chemistry (Eds.: R. Gleiter, H. Hopf), Wiley-VCH, Weinheim, 2004.

[5] J.-C. Tseng, S.-L. Huang, C.-L. Lin, H.-C. Lin, B.-Y. Jin, C.-Y. Chen, J.-K. Yu, P.-T. Chou. T.-Y. Luh, Org. Lett. 2003, 5, $4381-$ 4384.

[6] a) S. P. Karna, Y. Zhang, M. Samoc, P. N. Prasad, B. A. Reinhardt, A. G. Dillard, J. Chem. Phys. 1993, 99, 9984-9993; b) H. Pan, X. Gao, Y. Zhang, P. N. Prasad, B. A. Reinhardt, R. Kannan, Chem. Mater. 1995, 7, 816-821; c) P. R. Varanasi, A. K.-Y. Jen, J. Chandrasekhar, I. N. N. Namboothiri, A. Rathna, 
J. Am. Chem. Soc. 1996, 118, $12443-12448$; d) I. D. L. Albert, T. J. Marks, M. A. Ratner, J. Am. Chem. Soc. 1997, 119, $6575-$ 6582.

[7] C. Hansch, A. Leo, R. W. Taft, Chem. Rev. 1991, 91, 165-195.

[8] a) I. D. L. Albert, T. J. Marks, M. A. Ratner, J. Am. Chem. Soc. 1998, 120, 11174-11181; b) H. Kang, A. Facchetti, P. Zhu, H Jiang, Y. Yang, E. Cariati, S. Righetto, R. Ugo, C. Zuccaccia, A. Macchioni, C. L. Stern, Z. Liu, S.-T. Ho, T. J. Marks, Angew. Chem. 2005, 117, 8136-8139; Angew. Chem. Int. Ed. 2005, 44, 7922-7925; c) C. M. Isborn, E. R. Davidson, B. H. Robinson, J. Phys. Chem. A 2006, 110, 7189-7196.

[9] a) C.-F. Lee, L.-M. Yang, T.-Y. Hwu, A.-S. Feng, J.-C. Tseng, T.Y. Luh, J. Am. Chem. Soc. 2000, 122, 4992-4993; b) C.-F. Lee, C.-Y. Liu, H.-C. Song, S.-J. Luo, J.-C. Tseng, H.-H. Tso, T.-Y. Luh, Chem. Commun. 2002, 23, 2824-2825; c) C.-Y. Liu, T.-Y. Luh, Org. Lett. 2002, 4, 4305-4307; d) C.-M. Chou, W.-Q. Chen, J.-H. Chen, C.-L. Lin, J.-C. Tseng, C.-F. Lee, T.-Y. Luh, Chem. Asian J. 2006, 1, 46-55; e) for a review, see: T.-Y. Luh, C.-F. Lee, Eur. J. Org. Chem. 2005, 3875-3885.
[10] a) J. E. McMurry, M. P. Fleming, J. Am. Chem. Soc. 1974, 96, 4708-4709; b) J. E. McMurry, Chem. Rev. 1989, 89, 1513-1524; c) M. P. Fleming, K. L. Kees, L. R. Krepski, J. E. McMurry, J. Org. Chem. 1978, 43, 3255-3266.

[11] a) D. Roberto, R. Ugo, S. Bruni, E. Cariati, F. Cariati, P. Fantucci, I. Invernizzi, S. Quici, I. Ledoux, J. Zyss, Organometallics 2000, 19, 1775-1788; b) I. Ledoux, J. Zyss, Chem. Phys. 1982, 73, 203-213; c) K. D. Singer, A. F. Garito, J. Chem. Phys. 1981, 75, 3572-3580.

[12] L.-T. Cheng, W. Tam, S. H. Stevenson, G. R. Meredith, G. Rikken, S. R. Marder, J. Phys. Chem. 1991, 95, 10631-10643.

[13] a) C. R. Moylan, S. Ermer, S. M. Lovejoy, I.-H. McComb, D. S. Leung, R. Wortmann, P. Krdmer, R. J. Twieg, J. Am. Chem. Soc. 1996, 118, 12950-12955; b) B. J. Coe, J. A. Harris, B. S. Brunschwig, J. Garin, J. Orduna, J. Am. Chem. Soc. 2005, 127, $3284-3285$; c) H. S. Nalwa, T. Watanabe, S. Miyata, Adv. Mater. 1995, 7, 754-758; d) S. D. Bella, I. Fragalà, I. Ledoux, J. Zyss, Chem. Eur. J. 2001, 7, 3738-3743. 